\title{
The cellular factor Ku80 modulates retroviral expression in rodent and human cells
}

\author{
A Maurin, G Manic, F Subra, P Tauc, S Bury-Moné* and JF Mouscadet
}

Address: LBPA, UMR8113, IFR121, ENS-CACHAN, 94230, France

* Corresponding author

from Frontiers of Retrovirology: Complex retroviruses, retroelements and their hosts

Montpellier, France. 2I-23 September 2009

Published: 24 September 2009

Retrovirology 2009, 6(Suppl 2):PI8 doi:10.1 I86/1742-4690-6-S2-PI8

This abstract is available from: http://www.retrovirology.com/content/6/S2/PI8

(c) 2009 Maurin et al; licensee BioMed Central Ltd.

\section{Background}

DNA repair factors are putative effectors for cellular response to foreign DNA invasion since they specifically recognize DNA anomalies. The heterodimer Ku70/80 is the DNA-binding component of the DNA-PK complex required for the nonhomologous end-joining pathway (NHEJ) of double-strand break repair. It participates in numerous nuclear processes, including telomere and chromatin structure maintenance, replication, and transcription. We have observed a nuclear translocation of Ku80 following retroviral transduction, suggesting that it could correspond to an active response of the cell to infection. However, conflicting results concerning positive or negative effects of Ku80 on retroviral cycle are reported. Our aim was to clarify the role of Ku80 during retroviral infection.

\section{Materials and methods}

We therefore conducted a systematic analysis of retroviral integration and expression from a collection of gammaretroviral and lentiviral vectors or viruses transducing the $g f p$ transgene under viral (native LTR or CMV) or cellular (hPGK) promoters. With respect to human cells, the investigation of $\mathrm{Ku}$ impact on retroviral transduction is confronted with the problem of the strict requirement of $\mathrm{Ku}$ for cell survival. Here, we explore the roles of Ku80 within a new model of human cells partially depleted in Ku80 (epithelial cell lines HCT116 WT or heterozygote $\mathrm{Ku} 80+/$ - derivates) in parallel to the rodent model of complete depletion (hamster cells xrs 6 versus their parental line $\mathrm{CHO}$ and xrs6 line expressing human Ku80).

\section{Results}

The rate of integrated provirus estimated by Q-PCR does not vary depending on $\mathrm{Ku}$ status in these cellular models. While Ku80 depletion leads to an increased expression of all vectors within rodent cells, it is associated with a decrease of transgene expression under the only control of HIV LTR in human cells, independently of the presence of HIV accessory proteins. The impact of Ku80 on transgene expression could not be observed from plasmidic constructs, suggesting that its action requires its recruitment during retroviral transduction.

\section{Conclusion}

These results highlight the importance of Ku80 in the control of the retroviral expression, and the complexity of its action associated to real differences between the models. We propose that differences on the proviral environment depending on $\mathrm{Ku}$ status could have opposite consequences on transgene expression in rodent or human cells. Our study confirms that Ku80 promotes HIV multiplication in human cells. 